\title{
Security Enabled Parallel Connection for Intercom
}

\author{
Mubarak Nasser Kalif AL-Hatmi ${ }^{\mathrm{a}}$, Jibreal Khan ${ }^{\mathrm{a}}$, Sumesh E.P
}

\begin{abstract}
The paper is intended to keep up security amongst 4 parallel telephones associated with a solitary telephone cable wire. The proposed system provide near independent line like performance for the set of 4 intercoms line. At the point when two or more telephone is associated with a solitary telephone wire line, anybody can pick up telephone to attend the discussion on other end. The projected framework gives an answer for security amongst the telephones associated. So as to meet the prerequisite we are utilizing four phones associated as a part of parallel throughout solitary phone cable line with every phone associated through communicate a transfer in the framework. At the point when any of phone is picked up every single other telephone are disengaged by the transfers through a configuration plan of opt couplers, the consequence of that is provided to a code able Arduino. The Arduino drives signal to a seven segment demonstration to show which phone is picked up, whereas different phones are disengaged by particular transfers with assist of Relay-Driver Integrated Circuit connected to Arduino. The system can be utilized in home and workplaces there two or more phone is associated in parallel throughout a solitary phone line wire. The venture is reasonable for both approaching and going outward calls.Facilitate the venture can be upgraded by including more numeral of telephones with intercom service. An approaching caller ID service can likewise add further to this.
\end{abstract}

Keywords: intercom; arduino; exchange; relay;

\section{Introduction}

The fundamental aim of the project is to keep up data that is auto security for another person in the area of broadcast communications.

The project or venture is intended to keep up secrecy between 4 parallel phones associated with a solitary phone line. This is produced to flame out hacking of data in correspondence framework. In order to get together this prerequisite we are utilizing four phones associated parallel throughout a solitary phone line. At the point when more than one telephone is associated with a solitary phone line, anybody can lift telephone to listen to the discussion on other one. The proposed framework gives answer for secrecy between phones associated.

As to meet this prerequisite we are utilizing four phones associated in parallel throughout a solitary phone line with every phone associated throughout relay in the framework. At the point when any of the phone is picked up, there lay with situates with association and current flows furthermore, creates the Integrated Circuit OptoCoupler MCT23, and output is nourished to code able Arduino, furthermore, transmit signal to show which phone line wire is picked up in seven Segment show, whereas different phones will stumble off by creating relay open or off by the help of Relay - Driver Integrated Circuit (ULN2003). At the point when any of phone is lifted every single other telephone are disengaged by relays throughout planning of opto-couplers, the yield of that is provided for a programmable Arduino family.

The Arduino sends signal to a seven Segment demonstration to show that phone is lifted, while different phones are disengaged by individual relays with the help of Relay Driver IC interfaced to Arduino.

This Project can utilize as a part of houses and workplaces there more than one phone is associated in parallel throughout a solitary phone line. The project is appropriate for both approaching and going calls. Facilitate the project can be improved by including more numeral of telephones with intercom service. An approaching caller identification service can likewise add to it. [1].

\section{Project Background \\ 1.1 Project background}

In the good old days, maybe when we had a modest bunch of clients, we connected Intercom to Outreach since it was quick to pick up, and met our guidelines of an all-around composed item. For those of us that are less recognizable, Intercom is in-application notices framework that incorporates into application two way talk between end clients and organization representatives.[2].

We are at a standstill Intercom clients for their in-application notifications to end clients. It's hard to be incredible at all things, and they are still the pioneer at this.

In Intercom, there is no thought of waiting that implies there is no simple path for a Success Team associate to comprehend what they have tended to, and what necessitates their consideration.

The field of innovation identifies with disseminated sound or video frameworks and intercom frameworks for the most part, and all the more especially, to a digital intercom arrangement that gives multi-source, multizone disseminated sound or video and 2-way intercom abilities for existing house and workplace uses in light of correspondence over existing power lines.([4].

In Intercom, there is no understanding of a group that we can dispense it to. Despite everything that has faith in Intercom for informing with declarations in application, and for movement based correspondence. They are hands-down best at this, and it would like to develop as an organization in different regions. 
An office intercom is helpful for any entrepreneur, whether they have general guests or they are shut site. Whatever the extent of organization or motive of the workplace, there are various advantages to having the intercom professionally introduced. [3]

Reception security

Security is critical wherever we work, from pinnacle secrecy government locales throughout little branch workplaces. An intercom framework implies entrance can simply be observed, and is particularly essential when there is no formal gathering range.

They can be utilized as between floor gadgets. That implies entry can be controlled inside the association, giving staff diverse levels of freedom. Inward intercom is a superb approach to dissuade would-be criminals on the off chance that they can't get to something besides the ground floor.

The concept behind this is generation of a call signal by means of electronics involved which is transmitted by the intercom master unit which is also called as intercommunication system. This is transmitted to the number of remote units which make use of these signals for generation of an audio alert or call on selected remote units.

Design and analysis:

Design Configuration is phase where every genuine structure related information and method will be bored down. Similar to further indoctrination and embedded exercises, this project is moreover depending on constant arrangement to reproduce simulate or imitator given date and determination to get genuine yield

The secure connection plays an important role in everyone's life. In this case also we are talking about secure connection of the parallel connected intercom. This solution gives the in depth analysis of the topic considering various parameter across this project. In this work we have talked in detail about design.

process followed, what is risk criteria in this work, what flow model is followed. All points are being given as summary initially to just give idea about what is being communicated in the project. Finally after designing part we have taken a review of the work.

This chapter comprises particulars and clarification about system block diagram, flow chart, technical requirements. Also, it explains the reasonable parts of the system.[5]

\section{a. System Design:}

Design Configuration is central part of any project which show method, methodology, purposes of intrigue and impediments nearby the trials required to run framework module adequately. On for the most part, this venture is also depending on the system block duagram outline which illuminates parts anticipated that would develop for such purpose

\section{b. Block diagram:}

To portray especially described application, this is basic to first clear up all foremost and insignificant sections in venture. This portion will afterward crumble into a couple areas in perspective of need and headway reason. Taking after is outline that depict the structure block diagram.

The main telephone line is connected to the Arduino CPU extension program for telephone exchange. This is used to switch between the different telephone lines in the intercom system. The switching between different telephone lines in the intercom system is done by the help of relay incorporated in the system shown in Fig.1

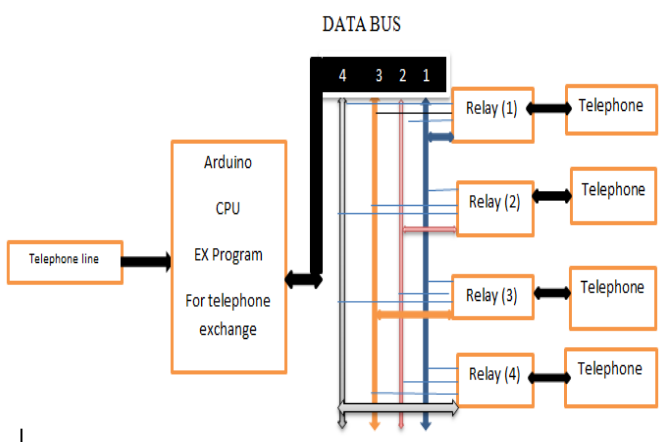

Fig 1. Block diagram of exchange system

The arduino gives command to the exchange switch to make a connection between the requisite telephone lines.

Figure 2 shown the intercome circuit connections by using 4 telephones connected with one line. When line on the all phones will ring, the first telephone pickup the rest discounted.As the moment the 7 segment will show the number of which phone is connected .There is switch to exchange the line between the telephone. When the line number one connected and wants to exchange the call to another one just press the number of switch and the call directaly exchange.

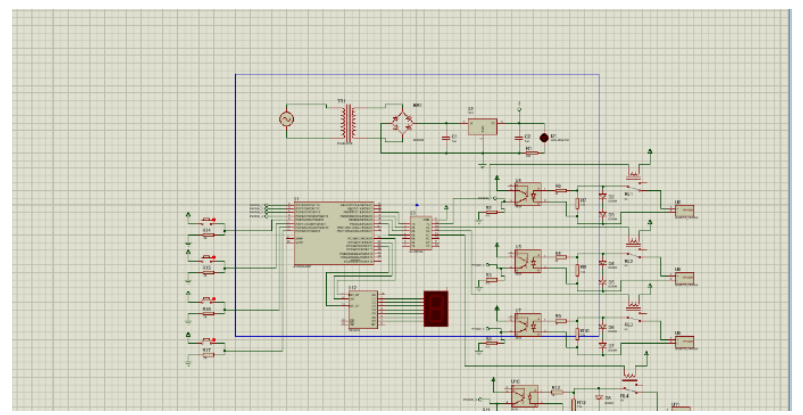

Fig.2 . Circuit diagram 


\section{PROJECT DESIGN}

a)Collecting data sheet and components relevant with the project by one week collected all equipment's, except one changing of switch by using the DTMF to reduce the cables connections.

b) I do the simulations of the circuit by using the Proteus programmer as shown in Fig. 3.

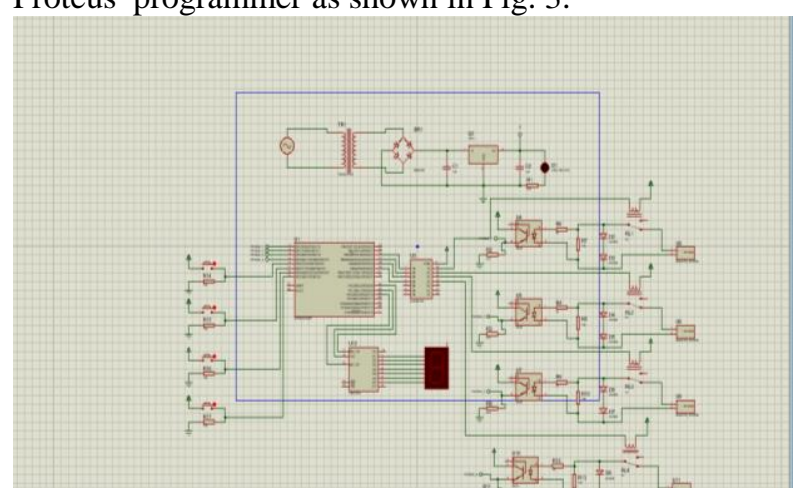

Fig.3 . System schematic diagram in Proteus.

c)First, I used the bread board to testing the circuit of ON/OFF hook by using two telephones

d)connected with one line cable. The result measure the current and voltage in both process .

e)Second, connected 7 segment and programmer in the chip of microcontroller.

f) Third, connected the rely with ON/OFF hook circuit by using two telephone and the result is shown in Fig.4.

g)I tested the DTMF testing, but no way to connected as switch as shown in Fig. 5.

h)Finally ,I solder all equipment and test it as shown in Fig.6.

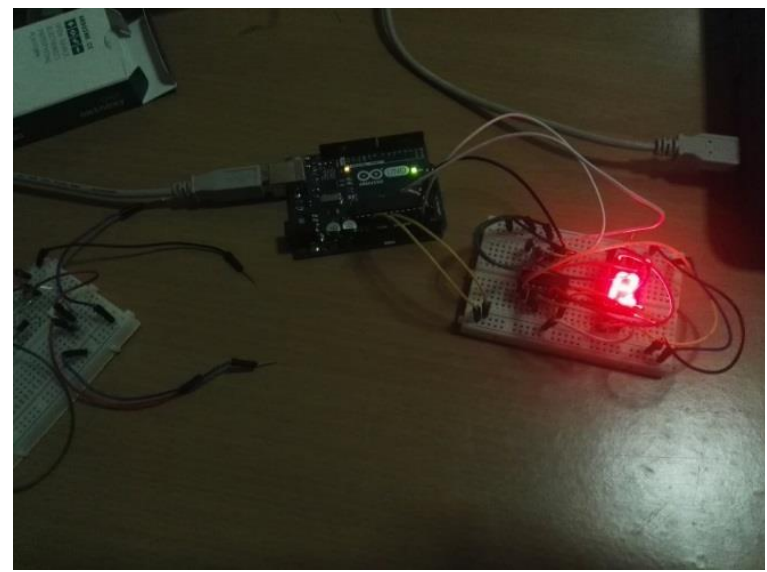

Fig. 4. Hook circuit functionality

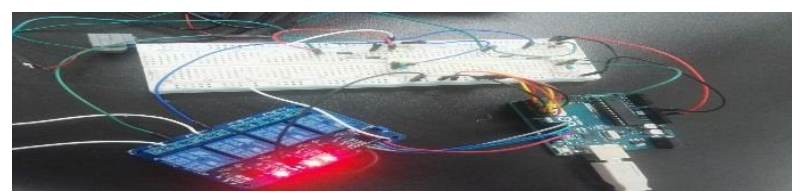

Fig. 5. DTMF testing

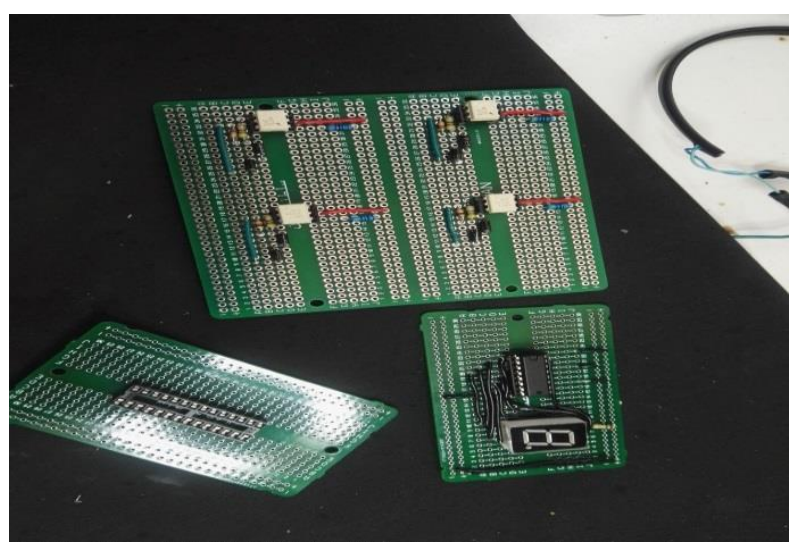

Fig. 6. Soldered system.

\section{III. . CONCLUSION}

The secure connection plays an important role in everyone's life. In this case also we are talking about secure connection of the parallel connected intercom. This solution gives the in depth analysis of the topic considering various parameter across this project. In this work we have talked in detail about design process followed, what is risk criteria in this work, what flow model is followed. All points are being given as summary initially to just give idea about what is being communicated in the project. Finally after designing part we have taken a review of the work.

The Home Security Intercom Control System is constructed and looked at utilizing 2 remote ends. Development and establishment of the remaining ends is in advance. The framework functions that have been tartan and worked acceptably are: interruption alert detecting; temperature detecting and, control of warming and aerating and cooling; main or master intercom abilities at every remote end; stereo organize and selfchecking of framework yields and power supplies.

The framework is extremely adaptable as a result of its Arduino controller and postponed work execution, and gives a great deal more ability than isolate frameworks could have given. The finished framework cost of around is extensively more practical than the buy of independent frameworks to actualize every functions.

The chief objective of the venture is to studied and design implemented to show how security enabled parallel connection for intercom implementation. 
The work is about intercom communication design for parallel networks which is secure. In this work securely designing the circuit is more important. Various aspects are talked in this work with proper elaboration about various internal sub topics. Design part is handled with the care. Finally we have concluded the work with the remarks of the established design objectives.

References

[1] Noller, D.L., 1978. Telephone, intercom and remote control system. U.S. Patent 4,100,375.

[2] Nigel Brent, SERIES \& PARALLEL SPEAKER WIRING Nigel B Design, Inc, 2002.

[3] Sumiya, H., Shinozaki, T. and Nakata, K., Aiphone Co., Ltd., 2003. Intercom system for a building or apartment house. U.S. Patent 6,671,360.

[4] Jeffrey Vaughn Wilson,System and method for integrated intercom and distributed audio/video system with security interface US $20090092236 \mathrm{~A} 1,2009$

[5] Manning, F.B. and Vance, W.H., Zoom Telephonics, Inc., 1999. Parallel-connected dialing signal transmission-inhibiting device for data transfer over a telephone link. U.S. Patent $5,898,756$.

[6] Halin, H.J., Bührer, R. and Halg, W., 1980. The ETH multiprocessor project: parallel simulation of continuous systems. Simulation, 35(4), pp.109-123. 